\title{
Integration of Reasoning and Wellbeing on the Lesson Plan and Implementation in Learning
}

\author{
Reti Tresnawati \\ Indonesia University of Education \\ Biology Education Department \\ Bandung, Indonesia \\ retitresnawati@gmail.com
}

\author{
Ari Widodo \\ Indonesia University of Education \\ Biology Education Department \\ Bandung, Indonesia \\ widodo@upi.edu
}

\author{
Widi Purwianingsih \\ Indonesia University of Education \\ Biology Education Department \\ Bandung, Indonesia \\ widi.purwianingsih@yahoo.com
}

\begin{abstract}
This research aimed to analyze the teachers' ability in integrating reasoning and wellbeing on lesson plan and analyze implementation of the lesson plan in learning. This research was a case study research. The subject were two biology teacher of junior high school in Bandung. Method of data collection used was through the triangulation of data integration reasoning and wellbeing on lesson plan and analyze of video recordings of learning. The results showed that both teachers were already able to integrate reasoning and haven't been able to integrate wellbeing on the components of lesson plan.
\end{abstract}

Keywords—reasoning; wellbeing; lesson plan.

\section{INTRODUCTION}

Efforts to improve instructional programs in sharpening competence and professionalism will be done by creative teacher [16]. In addition to the lesson plan, the preparation of learning is developed a form of professional development by teachers that is Pedagogical Content Knowledge (PCK). The teacher's knowledge of content and pedagogy are combined in the PCK. Development of PCK is using instruments with a framework that consists of two elements, namely Co-Re and PaP-eRs [9]. Co-Re used as instruments that measure content knowledge of teachers. PaP-eRs are used as instruments that measure the pedagogical ability of teachers. This teacher professional development program was applied before and after study. The relevance of the PCK will be shown when the teacher has designed Co-Re, and then the teachers can integrating these aspects at the Co-Re on the components of the lesson plan. Furthermore, lesson plan will be implemented into learning. To see the success, difficulties and follow-up of learning teachers devise a PaP-eRs as a record of reflection after the implementation of learning. PaP-eRs are useful to see the success, difficulties and follow-up of a study which has been carried out. If there is a section on learning activities that are considered to be weak and difficult to be carried out by teachers, then the teachers will be looking for a way to fix it in the next learning.

The components of the education system in a central position are occupied by a teacher [16]. A good teacher will carry out its task in the process of teaching and learning at the same time support the educational program implemented in a country. The teachers are a profession that requires special skills and originate from the institution. To become an professional teacher knowledge and skills needed in order to support success in carrying out its tasks. In the process of teaching and learning, teachers are assigned to make the preparation, carrying out activities of teaching and learning, student assessment, and utilizing feedback.

In making the ideal preparation, teachers are required to have a number of abilities. First, the teacher is required to master the subject matter to be delivered as well as relevant to the purposes of learning and evaluation tools. Second, teachers are required to make the learning objectives that correspond to the capabilities of the students. Third, teachers are required to draw up the appropriate evaluation tools with the goal of learning. Fourth, teachers are required to design learning experiences that make it easy for students to understand the subject matter. Fifth, the teachers are required to know and understand the various kinds of approaches, learning theory, method, and media of instruction. In order to make the learning process that was implemented successfully, it needs to be organized "teaching and learning strategy". Teaching and learning strategies were needed by teachers when composing preparation. In other words, teaching and learning strategy is the preparation of a plan the learning activities required in the 
teaching activity to achieve an optimal student learning outcomes with tailoring the school curriculum [16].

The planning of the preparation is poured in the form of the lesson plan [10]. Planning the teaching is designed as the directions of activities in achieving the objectives, as the archetypal when arranging tasks and authority in every element related activities, working as a guide for teachers and students, as a measuring instrument for the effective absence of a job (teaching), and to save time, costs, energy and tools.

Lesson plan outlined from Co-Re that has been designed by the teacher to direct learning activities of students in an attempt to achieve basic competencies. Teachers are obliged to draw up a complete and systematic lesson plan on units of learning in order for education to take place in a fun, challenging, interactive, inspiring, and can motivate students to participate actively. Lesson plan is designed for each of the basic competencies may be exercised for one meeting or more [1]. The components contained in the lesson plan include: (a) The identity of the subjects as components that includes educational units, classes, semester, or programs, subjects or themes of the lessons, and the number of meetings. (b) Standards of competence is qualifications minimum ability students by illustrating the mastery of knowledge, attitudes, and skills expected by students at any grade or subjects in a semester. (c) Basic Competencies are some of the skills that must be mastered by students in certain subjects as a reference preparation of indicators of competence in a lesson. (d) Indicators of competence is student behavior that can be measured or observed. It is to point out certain basic competence achievement which became a reference for the assessment of subjects. The formulation of indicators of achievement of the competencies using the verb operations that can be observed and measured, which includes the knowledge, attitudes, and skills. (e) Learning objectives contains a depiction of the process and the results of the study are expected to be reached by the student in accordance with the basic competencies. (f) Analysis the subject matter includes facts, concepts, principles, and procedures that are relevant, and are written in accordance with the achievement of indicators. (g) Allocation of time may be determined in accordance with students' need in the achievement of basic competencies and learning load. (h) The method of learning for create learning situation and process learning which support students reaching basic competencies or a set of indicators has been established. The situation and condition of the students, as well as the characteristics of each indicator and the competence achieved in each subject become election method the basics of learning. (i) Activities or learning step consists of activities beginning or introduction, the core activities and the end of activities. Early activity were the introduction on learning that contains activity for evoking motivation and focus the attention of the students to participate actively in the learning process. The core activity is the core of the learning process to achieve basic competencies. Learning activities are performed interactively, inspiring, motivating students to participate actively, fun, challenging, and provides enough room for initiative, creative, independent in accordance with the talents, interests, and physical and psychological development of students. The core activities are carried out in a systematic and systemic through the process of elaboration, exploration, and confirm. The final activity is an activity that is done to the activities of learning that can be implemented in the form of a summary or conclusion, assessment and reflection, feedback, and follow-up. (j) Assessment of learning contains procedures and instruments of assessment processes and results of student learning. Assessment of learning needs to be related indicators of achievement of the competencies refer to the standard assessment. (k) Learning resources used are based on the standard of competence, the competence base, learning materials, learning activities, and indicator competence achievement [1].

Science literacy development across the country involving students' needs is being focused on the development of the ability of reasoning, the nature of science and its knowledge content [7]. In this case, the teacher is required to have such competence. Scientific reasoning is seen as the ability to define the scientific skills, plan a way to answer questions, analyze data, and interpret the results [2]. Scientific reasoning is seen as a collection of inquiry on the process of thinking skills such as identifying problems, devise and propose a hypothesis, manipulate variables, carry out experiments, observing and evaluating the evidence, draw conclusions and arguments [18]. Learning that focuses on the scientific reasoning is usually contains a task that consists of a question or problem that make students think so use and develop a conceptual knowledge of students to a phenomenon. Reasoning is used to connect two parts of an argument that is a claim with evidence [5]. The Toulmin's Pattern can be used to assess whether or not a strong making it easy in analyzing arguments. Components of the argument consist of six components, namely claim, data, warrant, backing, qualifier and reservation [5]. Reasoning can be integrated in the PCK by using the Co-Re instruments. Reasoning on the component of lesson plan can be integrated on the competency standard or basic competencies, core competencies, indicators, goals, measures or activities learning and learning assessment.

In the PCK is not only focused on knowledge related to content [2]. However, combined with the knowledge of pedagogy with the way teachers view and understand the associated student psychological wellbeing. So, accomplished student are satisfaction in learning. It is relevant that the process of teaching and learning not only convey the sheer concept, but it needs to be cultivated and attitude values on students who are learning [16]. Attitudes and values is part of wellbeing. The need for integration of the students' wellbeing at the school because the school is not precisely be environment that results in students less comfortable, less positive and feel under-appreciated in all schools. For example, peers student can do bullying, and teachers who are judge or drop the confidence of students. Students' wellbeing defined as the ability of the student in carrying out his duties in the school environment [4]. Wellbeing is divided broadly into five domains i.e., cognitive, affective, social, physical and economic [11]. However, only the cognitive domain which can be implemented on the learning activities in school due to the cognitive domain can be measured during learning activities. On the preparation of learning, wellbeing can be 
integrated in the PCK by using the Co-Re instruments. Wellbeing can also be integrated in the component of lesson plan on standard competences or basic competencies, core competencies, indicators, goals, measures or activities learning and learning assessment. Educators at the school are expected to design and facilitate the wellbeing of students with cognitive focusing related to confidence, health or attitude that is rewarding, creative thinking and skill in problems solving. So, wellbeing can contribute to student learning outcomes. Scientific reasoning also has an important role in problems solving [6]. From the statement, it can be interpreted that wellbeing can support the learning that develops the capability of reasoning.

This research sought to uncover the professional development of teachers. These research analyzed through lesson plan were integrating reasoning and wellbeing and the implementation of the lesson plan in learning. It is aimed to analyze the teachers' ability in integrating reasoning and wellbeing at the component of lesson plan, and analyze the implementation of the lesson plan in learning. The results research can be considered to contribute to develop the ability of students' reasoning and student's wellbeing through the integration reasoning and wellbeing in the component of lesson plan.

\section{RESEARCH METHOD}

This research was a case study research. A case study was a research design that is analyzed in depth about a case on one or more individuals. Case study research was limited by time and implemented over a long period of sustained [3]. The subjects were twobiology teacher of Junior High School in Bandung. This research aims to analysis the ability of teachers in integrating reasoning and wellbeing of students on lesson plan and analyzed implementation of the lesson plan in integrating learning reasoning and wellbeing. Method of data collection used was through the triangulation of data integration reasoning and wellbeing on lesson plan and analyzed of video recordings of learning.

\section{RESULTS AND DISCUSSION}

\section{A. The ability of teachers in integrating reasoning and wellbeing on lesson plan.}

Learning implementation plan contains components namely identities subjects, competency standard or basic competencies, core competencies, indicators, objectives, materials analysis, learning activities or measures, methods, media, learning resources and learning assessment. Reasoning and wellbeing can be integrated in the lesson plan component on standard competences or basic competencies, core competencies, indicators, goals, measures or activities learning and learning assessment.

In General, the two teachers were already able to integrated reasoning on the components of lesson plan. Teacher A began integrated reasoning at core competencies III and core competencies IV to tailored curriculum 2013. Furthermore, teachers with integrated reasoning on basic competencies, learning objectives, indicators, all step activities learning and learning assessment. On the steps of learning and assessment, teacher A gives a lot more questions that stimulate students to developed reasoning ability and argument. This is in line with the summarized that students involved in argue can help students to build knowledge [13]. This happens because students will strive to develop high level thinking ability and his thought. In addition, the teacher A explored further answers by asking the students more reason than any answers that addressed the students. For example, "what are the factors that effect on melting ice cubes in the experiment? why? Explain your answer!".

Reasoning began integrated by Teachers' B since the basic competencies and competency standards tailored to KTSP curriculum. Furthermore, He was the integrated reasoning on indicators, learning objectives, all step activities learning and assessment. On the steps of learning and assessment, teacher B also provided questions that stimulate students to developed reasoning ability and argument. In addition, Teachers B explored further answers by asking the students more reason than any answers that addressed the students. For example, "What are the reasons that caused the wet season and the dry season suffered a change in time? Why? Explain your answer!". This is in line relevant with the opinion that the reasoning or argument was a process to find a reason [6]. When students provided some strong reasons in related learning argumentation in class, and then the argument emerge from the students need to be developed and verified again [12]. Students can be facilitated by a representative picture of the media to develop the capability of reasoning [17]. Furthermore, the reasons who has given and verified by the students justified based on the theory and strong evidence. The verification process was generating a strong link between theory, evidence, and the claim. To be able to developed the capability of reasoning required method or strategy that can developed and familiarized the students thought processes so that help students developed the ability of reasoning [8].

In General, the two teachers haven't been able to integrated wellbeing on the components of lesson plan. Teachers A integrated wellbeing on core competencies I, core competencies II, basic competencies, indicators, all step activities learning and learning assessment. Teachers A integrated wellbeing adjusted to curriculum was being used so that it can focus on wellbeing. Teachers A integrated wellbeing on indicators, but not integrated wellbeing at learning objectives. The planning of the preparation was poured in the form of lesson plan as the directions of activities in achieving learning objectives [10]. Therefore, assessment of learning that should be used to evaluate the learning objectives cannot be used. Teacher A provided a variety of instructional media to be able to facilitated students to understand the material or content. The students can have learning experience a lot to understand the concept. In addition, Teacher A gave students a worksheet that contains more reasoning questions so that students were more developed the ability of reasoning.

Teacher B only integrated wellbeing in all steps of the learning activities, the early activity, the core activities and activities tailored to the KTSP curriculum was being used. Therefore, teachers' B does not integrate the wellbeing into basic standards of competency, base competencies, learning objectives, indicators, and assessment. Teacher B facilitated students' wellbeing by making the reasoning questions at each 
step of the learning activities to facilitated understanding of the concept.

\section{B. The implementation of lesson plan.}

In general of the two teachers to implemented reasoning that was designed for the lesson plan on learning and teaching activity by way of provided questions that explores further the reasons of students' answers. This was relevant to the summarized that the scientific reasoning was seen as the ability to define the scientific skills, plan a way to answer questions, analyze data, and interpret the results [2]. Learning activities that have been carried out by Teacher A through the observation was as follows:

Teacher : How did the relationship between the following factors: the volume of ice cubes (poles), 100 watt light (the Sun), the spaces of existence function of various plants (the ecosystem) and the time around 10 until 30 minutes? Explain, why?

Student : If one factor was changed, it will influence others.

Teacher : If the intensity of the light from the Sun or a lamp was raised again, what will happen?

Student : It will affect to the environment and the weather.

Teacher : How about temperature?

Students: Temperatures are getting hotter or increase

Teacher : If the temperature rises, what will happen?

Students: The water volume will increase faster because the ice is melting.

Teacher : What will happen to the environment?

Student : It could be flood.

Learning from Teacher A had done in line with the opinion that the reasoning used to connect two parts of an argument that was a claim with evidence [5]. Students can made a claim that gained from the observations. Then, the teacher A delve of claim reasons made students. The reason that connects the claim with evidence obtained from the results of students ' observation.

The learning that has been designed by Teacher A on the lesson plan changed when implementations in learning and teaching activity. For teacher A, the changed can be shown to the core activity in the learning step. To observe a demonstration of the teacher concerning tools and influence radiation for the lamp on a simple Terrarium associated initial data of temperature before the experiment to be recorded by the students. Teachers A only call three students to other students observed and recorded the results of observations were made and informed by three students. When the students were doing the worksheet, teachers A also told other students to observe directly the terrarium interchangeably.

The questions from worksheet as not all were discussed. Only four questions were discussed with the teacher ask back the reasons of each student's answer to argue and discuss it with the other students in the class. For example, "in addition to the primary cause, are there other causes that can cause air pollution? Please tell to us? ". Students were expected to answer: smoke industry, cigarette smoke and fumes of burning garbage, because it will pollute the air. Teachers A explored to each group the reasons why smoke industry, cigarette smoke and fumes of burning garbage can disrupt air and cause a variety of ailments. It was concerned the content of substances from industrial fumes, cigarette smoke and fumes of burning garbage that can pollute the air and can cause illness. Furthermore, for confirmation and reinforcement teacher A gave two impressions video about global warming. At the end of the core activities, teacher A also gave reward to one person students who do not dispose of garbage in the classroom and not buying drinks in schools and also bring water from home. Reasoning on the learning that has been done by Teacher A, relevant with reasoning obtained through several activities such as; identify the problem, devise and propose a hypothesis, manipulate variables, carry out experiments, observing and evaluating the evidence, draw conclusions and arguments [18].

On implementation activities, the teacher A thought student's wellbeing with how to help the students to understand and mastery the subject matter by facilitating the students with a variety of media by terrarium, the original media, videos and demonstrations. Teacher A also provided a worksheet for students of observation terrarium and observation real media. In addition, Teacher A facilitated students to be able to mastery the subject matter by provided more questions that explored reasoning from the answers of the students so that students are more developed reasoning ability.

Teacher B implemented the reasoning that was designed from the lesson plan in teaching and learning activity by way of provided questions that explored further the reasons of student answers. Learning from Teacher B had done in line with the opinion that the reasoning used to connect two parts of an argument that was a claim with evidence [5]. Learning activities that have been carried out by Teacher B was as follows:

Teacher :Why the temperature in Tray 1 which closed by plastic get higher temperatures compared to the tray 2 not closed by plastic?

Students : Due to the sunlight into Tray 1 can't be reflected back to the outside of the plastic.

Teacher : Why?

Student : Because there are $\mathrm{CO} 2$.

The learning that has been designed by Teacher B on the lesson plan was changed when implementations in learning and teaching activity. For teacher B, the changed can be shown on early learning activities. Teacher B doesn't serve natural phenomena such as forest fires, floods, hurricanes, glaciers are melting, but rather just gave a question associated with environmental preservation efforts and living things. Every question asked in detail to the students and explored into the reasons of each student's answer. At the core of learning activities, teacher $\mathrm{B}$ did experiments with a one-time repetition. However, Teachers' $\mathrm{B}$ repair performed experiments with 3 repetitions. Teacher B gave the impression 
of a video about global warming and the student records summary global warming via video footage. This was done to get the abstractconcepts has not been obtained through experiments. Discussion on the activities, students were given questions to find a conclusion based on the results of the experimental activities. This was relevant to the opinion that learning was focused on scientific reasoning typically contains tasks that consist of a question or problem that make students think to develop a conceptual knowledge of students by phenomenon [18]. At the end of the learning activity, the teacher does not give an opportunity ask students, guiding students to make conclusions about global warming, and gave the task to summarize a variety of pollution due to the limited time.

On implementation activities, teacher B think of students' wellbeing by way of provided motivation to students, invited students understand the purpose of the learning material, gave the opportunity to the students to do experiments, and communicated the results of the observations of both individually and group. Students' wellbeing identified as students ' ability in carrying out his duties in the school environment [4]. This was relevant by Teacher B had done by facilitated the activities of experimentation, and provided worksheet. In addition, Teachers B divided students in groups in a small number of members, gave good response against the answers of the students, as well as provided a reward for students who answer questions.

\section{CONCLUSION}

In general the two teachers were already able to integrate reasoning and haven't been able to integrate wellbeing on the components of the implementation plan of instruction. The study of reasoning by both teachers implemented by way of provided question that explores further the reasons of students ' answers. Wellbeing at learning by the two teachers was implemented in a way to facilitated the students with the media, provided worksheets, provided more reason that explored the reasoning questions from the answers of the students so that students were more developing reasoning ability, provided the motivation to students, divided students in groups in a small number of members, gave good response against the answers of the students, as well as provided a reward for students who answer questions.

\section{Acknowledgment}

We are thankful to the teachers who participated in this study and to the Indonesia University of Education.

\section{References}

[1] BSNP, Permendiknas RI No. 41 Tahun 2007 tentang Standar proses untuk satuan pendidikan dasar dan menengah, Jakarta, 2007.

[2] C. T. Chen and H. C. She, "The Effectiveness of Scientific Inquiry with/without Integration of Scientific Reasoning". International Journal of Science and Mathematics Education, 20: 1-20, National Science Council, 2014.

[3] J. W. Creswell, Research Design: Qualitative, Quantitative, and Mixed Methods Approaches, USA, SAGE Publication, 2009.

[4] J. Fraillon, "Measuring Student Wellbeing in the Context of Australian Schooling:Discussion Paper",Commissioned by the South Australian department of Education and Children's services as an agent of the
Ministerial Council on Education, Employment, Training and Youth Affairs, 2004.

[5] E. S. Inch, B. Warnick, and D. Endres,Critical Thinking and Communication: The Use of Reason in Argument, Boston, Allyn and Bacon, 2006.

[6] W. Khan, and H. Ullah, "Scientific Reasoning: A Solution to the Problem of Induction", International Journal of Basic \& Applied Sciences, 10(3), pp. 58- 62,2010.

[7] K. Koenig, M. Schen and L. Bao, "Explicitly targeting pre-service teacher scientific reasoning abilities and understanding of nature of science through an introductory science course", Science Educator, Vol.21, No.2, 2012.

[8] A. Kurniadi, A. Widodo, D. Rochintaniawati, and Riandi, "Analisis reasoning skill siswa pada pembelajaran biologi SMA",Prosiding simposium nasional inovasi dan pembelajaran sains, 2015.

[9] J. Loughran, A. Berryn and P. Mulhall, "Understanding and Developing Science Teachers' Pedagogical Content Knowledge 2nd Edition",Rotterdam, Sense Publishers, 2012.

[10] A. Majid, "Perencanaan pembelajaran : mengembangkan standar kompetensi guru”,Bandung : PT. Remaja Rosdakarya, 2011.

[11] M. D.Nelson, D. W. Tarabochia, and R. L. Koltz, "PACES : A Model of Student Well-Being”, Journal of School Counseling, 2015.

[12] P. E. Newton, R. Driver, and J. Osborne, "The place of argumentation in the pedagogy of school science" International Journal of Science Education, 21(5), 553-576, 1999.

[13] K. Nichols, R. Gillies, and J. Hedberg, “Argumentation Based Collaborative Inquiry in Science Through Representational Work : Impact on Primary Students' Representational Fluency", Research in Science Education, 2015.

[14] Noble, et al., "Scoping study into approaches to wellbeing student",ACU National Australian Catholic University and Erebus International, 2008.

[15] NSW Department of Education and Communities, "The wellbeing framework for school",[Online] available: htttp//www.dec.nsw.gov.au, 2015.

[16] Rustaman, et al. "Strategi belajar mengajar biologi", Jurusan Pendidikan Biologi FPMIPA Universitas Pendidikan Indonesia, 2003.

[17] R. Tytler, V. Prain, P. Huber and B. Waldrip. "Constructing Representations to Learn in Science, The Netherland, Sense Publishers, 2013.

[18] C. Zimmerman, "The development of scientific reasoning skills", Development review 20, 99-149, 2000. 